\title{
Hydro-chemical effect of different quality of water on the behaviour of an expansive soil during wetting and drying cycles
}

A. R. Estabragh

Assistant Professor, Faculty of Soil and Water Engineering, University of Tehran, PO BOX 4411 Karaj 31587-77871, Iran

Tel: +982612241119

Fax: +982612226181

Email: raeesi@ut.ac.ir

\section{Moghadas}

Postgraduate Student, Faculty of Soil and Water Engineering, University of Tehran, PO BOX 4411 Karaj 31587-77871, Iran

Tel: +982612241119

Fax: +982612226181

Email: M.Moghadas@ut.ac.ir

\section{A. A. Javadi}

Professor, Computational Geomechanics Group, College of Engineering, Mathematics and Physical Sciences, University of Exeter, Devon, EX4 4QF, UK

Tel: +44 1392723640

Fax: +44 1392217965

Email: A.A.Javadi@exeter.ac.uk 


\title{
Hydro-chemical effect of different quality of water on the behaviour of an expansive soil during wetting and drying cycles
}

\begin{abstract}
:
The effect of quality of water on deformation, $\mathrm{pH}, \mathrm{EC}$ (Electrical conductivity) and osmotic suction was studied for an expansive soil during wetting and drying tests. The cyclic wetting and drying tests were conducted on samples of an expansive soil in a modified oedometer flooded with distilled, acidic and saline water. During the tests axial deformation of the samples was recorded continuously. $\mathrm{pH}$ and $\mathrm{EC}$ of pore water and reservoir water were measured through duplicated samples in a conventional oedometer. Osmotic suction was calculated based on the values of EC. The results show that the magnitude of deformation depends on the quality of the water and the deformation attained equilibrium condition nearly after four cycles. $\mathrm{pH}, \mathrm{EC}$ and osmotic suction were decreased with increasing suction.
\end{abstract}

Keywords: Expansive soil, wetting and drying, osmotic suction, EC, $\mathrm{pH}$ 


\section{Introduction}

Expansive soils are a group of soils that when in contact with water, they adsorb water and their volume is increased. Expansive soils exist in many parts of the world, specially in semi-arid areas (Fredlund and Rahardjo, 1993). They are usually clay soils and are comprised of very small plate-like particles with very high specific surface. The surfaces of the plate like clay particles have electrical charges. As the specific surface of clay particles increases, the role of the charged surface of clay particles becomes increasingly prominent (Mitchell, 1993). Therefore, increasing the specific surface of particles causes higher electrical charge, and hence more water can be adsorbed which in turn leads to greater swelling potential. Increasing the volume of expansive soil due to adsorbed water can damage structures, particularly light buildings, pavements and linear of the irrigation canals (Fredlund and Rahardjo, 1993 and Bell, 2000). The annual cost of damage due to expansive soils is estimated about $\$ 9$ billion per year in the United State that is more than the damages resulted from combined natural disasters such as floods, hurricanes, earthquakes and tornadoes (Jones and Holtz, 1973). An understanding of the behaviour of expansive soils is therefore needed in the design and construction of a wide range of structures. It is generally accepted that the mechanism of swelling is dependent on many factors such as initial water content, initial void ratio or unit weight, vertical stress and the type and amount of clay minerals of the soil (El-Sohby and Rabba, 1981 and Fredlund and Rahardjo, 1993). The quality of flooding water and pore water of soil has important effect on the potential of swelling. When a soil is flooded with a wetting liquid, osmotic suction is created between the flooding water and the pore water of the soil sample which has an impact on the swelling mechanism of the soil. Researchers such as Musso et al. (2003), Rao and Shivananda (2005) and Rao and Thyagaraj (2007) 
studied the behaviour of expansive soils flooded with different quality of water. They concluded that the concept of osmotic suction can be used to explain the swelling behaviour of expansive soils. The existence of gradient in the concentration of dissolved ions between two regions of a liquid, and separation of the regions by a semi-permeable membrane are two essential factors for occurrence of the osmotic suction. The behaviour of expansive soils was studied through cyclic wetting and drying tests by researchers such as Dif and Blumel (1991), Day (1994), Al-Homoud et al. (1995), Basma et al. (1996), Tripathy et al. (2002) and Alonso et al. (2005). They concluded that the potential of swelling is decreased with increasing the number of wetting and drying cycles until it reaches a constant value without any irreversible deformation. On the other hand Chu and Mou (1973), Osipov et al. (1987) and Day (1994) reported the opposite conclusion that the potential of swelling increases with increasing the number of wetting and drying cycles. Rao and Shivananda (2005) and Rao and Thyagaraj (2007) studied the effect of chemical gradient between the soil sample and flooding water on the swelling potential of an expansive soil. They conducted from the swelling tests on the samples that were amended by sodium chloride and calcium chloride and flooded by distilled water and also the samples that were prepared with distilled water and flooded with salty water (distilled water with different concentrations of sodium chloride and calcium chloride). They concluded that the chemical gradient is an important factor in swelling potential of a soil. It appears that the chemical gradient between the flooding water and soil sample (due to the quality of pore water and that of flooding water) has not been considered during cycles of wetting and drying. The quality of water is a very important factor in the development of chemical gradient and creation of osmotic suction between soil water and flooding water. The osmotic suction may lead to osmotic consolidation (Barbour 
and Fredlund, 1989). A review of the literature shows that the effect of osmotic suction has been studied on the potential of swelling but the effect of variations of osmotic suction on the swelling potential has not been considered during wetting and drying cycles. Therefore, the aim of this work is to investigate the variations of osmotic suction and $\mathrm{pH}$ during the wetting and drying tests for samples flooded with different quality of water.

\section{Material}

Soil

A number of wetting and drying tests were conducted in an oedometer on specimens of a highly expansive soil (according to the classification proposed by McKeen 1992). The soil that was used comprised a mixture of $20 \%$ bentonite and $80 \%$ kaolin. Tables 1 and 2 show the physical and chemical properties of the soil. The soil can be classified as clay with high plasticity $(\mathrm{CH})$ according to the unified soil classification system (USCS). Compaction test was performed according to the ASTM D698a2000. The results showed that the soil has an optimum water content ( $w_{\text {opt }}$ ) of $20.5 \%$ corresponding to a maximum dry unit weight $\left(\gamma_{\mathrm{dmax}}\right)$ of $16.1 \mathrm{kN} / \mathrm{m}^{3}$.

\section{Flooding water}

Three different kinds of water were used for flooding the soil samples during the wetting stage. These were distilled water, acidic water and saline water. Distilled water that was used had a $\mathrm{pH}$ of 7.2 and EC (Electrical Conductivity) of $14 \mu \mathrm{S} / \mathrm{cm}$. Acidic water was made by mixing $10 \mathrm{ml}$ of sulphuric acid with normality of 0.01 with $990 \mathrm{ml}$ of distilled water. Chemical tests showed that the $\mathrm{pH}$ and $\mathrm{EC}$ of this kind of water were 5.5 and $19 \mu \mathrm{S} / \mathrm{cm}$ respectively. Saline water was prepared by adding $2.5 \mathrm{gr}$ sodium chloride with $1000 \mathrm{ml}$ distilled water. $\mathrm{pH}$ and $\mathrm{EC}$ of this mixture were determined as 8.9 and $900 \mu \mathrm{S} / \mathrm{cm}$. 


\section{Sample preparation}

In the experimental work it is necessary to make samples in identical fashion in order to provide homogeneous and repeatable samples with the same initial fabric. A known mass of soil was mixed with required quantity of water (to a given water content equal to $17.5 \%, 3.0 \%$ less than the optimum water content from standard compaction test) in a try. Mixing of the soil and water was done in a tray by hand. To avoid loss of moisture and achieve equalisation of the moisture throughout the soil, it was transferred into a plastic bag and sealed for 24 hours. Then the soil was poured into a special mould as described in Estabragh et al. (2013) and compacted in a loading frame by static compaction in three layers to a vertical stress of $800 \mathrm{kPa}$ at a displacement rate of $1.5 \mathrm{~mm} / \mathrm{min}$.

\section{Experimental program}

The experimental program consisted of two parallel stages. The first one was performed in a modified oedometer to study the deformation of the samples under constant surcharge pressure during wetting and drying. The second stage of experimental was conducted on duplicated identical samples, in the same condition as the original samples in the first stage, for studying the chemical and physical behaviour of the soil. These stages were as follows:

a- Stage 1

A conventional oedometer was modified to allow testing under controlled temperature and surcharge pressure as described in Estabragh et al. (2013). The sample was placed in a ring, with the same dimensions as the consolidation ring. Porous stones were placed on the top and bottom of the sample and then the desired load was applied through a plate that was placed on the top porous stone. The sample was then loaded to a desired surcharge pressure which was kept constant until full deformation was 
attained. The sample was then flooded with desired quality of water and was then allowed to swell under the applied pressure. The drying stage was followed after completion of swelling. This stage was started by removing the water from the reservoir through a drainage valve. During the drying stage the temperature control was switched on and the temperature was kept constant $\left(45^{\circ} \mathrm{C}\right)$. Combination of one swelling and the subsequent drying stage is referred to as one cycle of wetting and drying. During these each cycle of wetting and drying the vertical deformation was recorded by using a dial gauge. Reading was continued until the vertical deformation reached a nearly constant value so, full swelling or shrinkage was attained. For the next stage the sample was flooded again with the same quality of water and then another cycle of wetting and drying was conducted. This procedure was continued until the equilibrium condition was achieved where the magnitudes of swelling and shrinkage were the same.

b- Stage 2

A number of identical samples were prepared with similar initial conditions as the main sample (used in stage 1 test). These specimens were exposed to the same cyclic wetting and drying under the same surcharge pressure as the main sample. At the end of wetting, the samples were dismantled. The $\mathrm{pH}$ and $\mathrm{EC}$ of the flooding water and pore water were measured, according to the ASTM standard procedure, at different times after flooding for different cycles of wetting and drying.

\section{Results}

Fig. 1 shows the deformation of the soil samples flooded with different quality of water under surcharge pressure of $20 \mathrm{kPa}$. This figure shows that almost all the deformations in all cycles are in compression except the first cycle. The deformations for the samples flooded with distilled, acidic and saline water in the first wetting stage 
are $0.43,0.63$ and $0.63 \mathrm{~mm}$ respectively and they changed to $0.58,0.83$ and $1.45 \mathrm{~mm}$ in the subsequent drying stage. Deformation is increased during wetting and decreased during drying stage by increasing the number of cycles. The equilibrium is attained in the fourth cycle for sample flooded with distilled water with nearly $1.0 \mathrm{~mm}$ deformation for wetting and drying. In the case of samples flooded with acidic and saline water, equilibrium is attained in the fifth cycle with deformations of 1.01 and $1.81 \mathrm{~mm}$ respectively. Figs. 2-4 show the variation of $\mathrm{pH}$ with time for different quality of flooding water. The measurement of $\mathrm{pH}$ was done 2 hours after flooding the soil sample. The results show that the $\mathrm{pH}$ of reservoir is increased sharply until about 8 hours after flooding and then with relatively milder deformation thereafter. The values of $\mathrm{pH}$ of the pore water are decreased during each cycle and with sharp reduction at the initial time of flooding and then it remains nearly constant. For both acidic and saline water the variation of $\mathrm{pH}$ is reduced by increasing the number of cycles. The results of EC for reservoir water and extracted pore water from the samples flooded with distilled, acidic and saline water are shown in Figs.5 -7. It is observed that the values of EC are decreased with increasing the number of wetting and drying cycles. The values of reservoir EC are increased with time for all cycles. The increase of EC is high from the start of the first flooding stage until about 8 hours after which it continues to increase in a linear fashion with small gradient. The initial values of EC are $0.302,0.402$ and $0.975 \mathrm{mS} / \mathrm{cm}$ for distilled, acidic and saline water in the first cycle after 2 hours of flooding and they reach $0.601,0.614$ and $1.58 \mathrm{mS} / \mathrm{cm}$ respectively after 8 hours. The final values of EC attained after 48 hours flooding, are $0.655,0.681$ and $1.609 \mathrm{mS} / \mathrm{cm}$ for distilled, acidic and saline flooding water respectively. Similar trends can be seen for acidic and saline flooding water. The results of EC for the pore water extracted from the sample show that the values of EC 
are decreased with time during each cycle for different quality of flooding water. The rate of reduction of EC is high from initial time of flooding until 8 hours and after that it remains nearly constant. These variations are opposite to those of the reservoir EC variation. After 2 hours of flooding the values of EC were measured as 15.3, 15.32 and $15.32 \mathrm{mS} / \mathrm{cm}$ for distilled, acidic and saline water respectively and they reached $14.75,14.83$ and 14.96 after 8 hours of flooding with different quality of water. The final values of them after 48 hours are $14.64,14.79$ and $14.89 \mathrm{mS} / \mathrm{cm}$ respectively. By increasing the number of cycles the rate of reduction becomes relatively small. Fig. $7 \mathrm{~b}$ shows that the values of pore water EC for saline water are 15.32, 14.96 and 14.89 $\mathrm{mS} / \mathrm{cm}$ after 2, 8 and 48 hours of flooding in the first cycle. These values are changed to the $14.5,14.41$ and $14.39 \mathrm{mS} / \mathrm{cm}$ after 2,8 and 48 hours respectively.

\section{Discussion}

It is resulted from Fig. 1 that deformation of the soil induced by the three different wetting fluids is not the same during cycles of wetting and drying and the deformation is increased with increasing the number of cycles. The samples were first wetted and vertical deformation occurred in all of them but during drying both the vertical and lateral deformations occurred in the sample. These deformations resulted in volumetric deformation of the samples. Therefore, the samples during wetting and drying experienced volumetric deformation (Faramarzi et al. 2012). It is observed from this figure (Fig.1) that the deformation due to saline and acidic water is more than the distilled water. It can be said that the saline or acidic water caused the degree of flocculation of fabric of soil to increase and it leads to greater deformation in the soil. It is resulted that the ability of saline water to increase the degree of flocculation is more than acidic water. These results are not in agreement with the findings that were reported by researchers such as Al-Homoud et al. (1995), Basma et al. (1996), 
Dif and Blumel (1991) and Tripathy et al. (2002) who indicated that the deformation is decreased with increasing the number of cycles. However, they are consistent with the results that were published by Osipov et al. (1987) and Day (1994) who showed that the deformation of the sample increased with increasing the number of cycles until the equilibrium was reached.

The results of $\mathrm{pH}$ for reservoir water and pore water are shown in Figs. 2-4. $\mathrm{pH}$ is an index that shows the acidity or alkalinity of a soil. By increasing the hydrogen ions in soil the $\mathrm{pH}$ of the soil decreases and behaviour of soil becomes acidic. The variation of $\mathrm{pH}$ affects the solubility of minerals of soil. The $\mathrm{pH}$ of pore water is changed during each cycle and by increasing the number of cycles.

Figs.5-7 shows the variations of EC during each cycle for different quality of water. EC shows the amount of total dissolved salts (TDS) or the total amount of dissolved ions in water. The amount of EC of pore water is reduced but that of the reservoir is increased. This indicates the movement of dissolved ions from pore water to the reservoir. However, by increasing the number of cycles the changes in $\mathrm{EC}$ becomes smaller. These conditions can be seen-in the fourth cycle for variations of $\mathrm{pH}$ and EC. It can be said that the variations of $\mathrm{pH}$ and EC are related to the fabric of soil. After about 4 cycles the deformation of the soil reached equilibrium, the fabric of soil sample reached a constant state and the change in the EC and $\mathrm{pH}$ became insignificant.

The surfaces of most clay particles (in dry or wet conditions) carry an unbalanced negative charge, which attracts cations. These positive ions become strongly attracted to a dry clay surface. In addition to the needed cations for the electrical neutrality of the clay surface, there are usually some salt precipitates that are combination of cations and anions. There is a range of dissolved salt concentration in the pore water 
of clay soil due to the weathering (Rogers et al., 1994 and Brady, 1984). The existence of dissolved salt concentration in the pore water of these soils could be caused by infiltration of landfill leachate, infiltration from brine or chemical spillage from industrial operations (Barbour and Yang, 1993 and Rao and Shivanada, 2005). These ions go into solution by adding water. Desorption of cations from the clay surface leads to a higher concentration of cations near the clay surface than the concentration of cations farther away, which makes the cations have a tendency to diffuse farther away. This tendency for diffusion is however, opposed by the attractive forces between the cations and the negative particle surface. The net result of these opposing trends is an ion distribution in the vicinity of the clay particles. This system of distribution of charge, along with the charged surface of clay is termed the diffuse double layer (Mitchell, 1993). The diffuse double layer can be developed for individual layers or clay platelets. The interaction of the diffuse double layers of neighbouring unit layers results a net repulsive force between them. Attractive forces however develop between two double layers approaching extremely close to each other. The attractive and repulsive forces between adjacent clay particles are as a result of the London vander wales and electrostatic forces respectively (Barbour and Fredlund, 1989). In many cases, the electrostatic repulsive forces between particles of clay is more significant than the attractive forces.

Before saturation, the soil samples are in unsaturated state. They have two suction components; matric suction that arises from capillary phenomenon in unsaturated voids and osmotic suction from the presence of salts in soil water (Fredlund and Rahardjo, 1993). The concept of osmotic suction and osmotic pressure can be used as an aid to find information about the physical process of swelling. It is accepted that the existence of a gradient in the concentration of dissolved ions between two regions 
of a liquid and separation of the regions by a semi-permeable membrane are two important factors for occurrence of osmotic pressure difference. A semi-permeable membrane prevents flow of the solvent but not of the solute. The attractive forces between the negatively charged surface of a unit layer and the attached cations prevent the diffusion of the cations away from the surface. This creates the effect of a semi-permeable membrane. Where diffuse double layers of two unit layers overlap, a dissolved ion concentration gradient occurs between the liquid within the diffuse double layer region and the bulk liquid. This concentration gradient causes the water to flow from the bulk water into the diffuse double layer region. As water flows into the diffuse double layer region, the pore water pressure in this layer increases, resulting in a pore water pressure gradient tending to induce flow into opposite direction to that caused by the concentration gradient. Therefore, the osmotic flow occurs from a solution of lower concentration to a higher concentration. If the clay particles in between act as perfect semi-permeable membranes, only water is exchanged between the clay voids and external solution in response to chemical concentration gradient.

When the soil sample is placed in the apparatus, it is in unsaturated condition. By inundating the sample with different quality of water (distilled water, saline water or acidic water) water flow from the reservoir to soil sample will be continued until the matric suction is dissipated and the sample becomes saturated.

Osmotic suction $(\pi)$ is developed between the inundating water and soil's pore water because of the different qualities of the two fluids. Researchers such as Fredlund and Rahardjo (1993) and Mata et al. (2002) presented a solution for estimating the osmotic suction from the EC of the solution. The USDA calibration curve that was presented by Fredlund and Rahardjo (1993) was used for estimating the suctions of 
compacted expansive soils. The USDA calibration curve relates the osmotic suction to the $E C$ according to the following relationship:

$\pi=31.92 E C^{1.08}$

[1]

where $\pi$ is the osmotic suction in $\mathrm{kPa}$ and $E C$ the difference between electrical conductivities of extracted water from the sample and reservoir in $\mathrm{mS} / \mathrm{cm}$.

Romero (1999) presented another relationship similar to the above equation that is dependent on the salt mass concentration. The osmotic suction was calculated based on the above equation by considering the values of reservoir and pore water EC for each cycle of test. Figs. $8-10$ show the variations of osmotic suction with time for different quality of flooding water. It is seen that the trend of variation of osmotic suction is similar to that of pore water EC and both osmotic suction and EC decrease with increasing the number of cycles .The variation of osmotic suction during each cycle is reduced with increasing the number of cycles. The difference between osmotic suctions at the initial time ( 2 hours after flooding) and final time (after 48 hours) is reduced with increasing the number of cycles. For distilled water the difference is $42.3 \mathrm{kPa}$ in the first cycle but it reaches $19.2 \mathrm{kPa}$ in the fourth. The quality of water is also important in the variations of osmotic suction. The changes in osmotic suction in the first cycle for distilled, acidic and saline water are 42.3, 32.8 and $46.4 \mathrm{kPa}$ respectively. These values reach $19.2,18.7$ and $27.6 \mathrm{kPa}$ in cycle 4 . It can be said from comparing these results that the saline water has a greater effect on creating osmotic suction. By increasing the number of wetting and drying cycles the changes in osmotic suction is reduced. Comparing the results for cycles 1 and 4 shows that, in all 3 cases, sharp changes in osmotic suction occurred in cycle 1 and then the rate of change became smaller. However, in cycle 4, the changes in values of EC and osmotic suction become relatively small and on the other hand deformation of 
samples reach a constant value nearly in cycle 4 . It can be said that the equilibrium condition for deformation corresponds to the equilibrium in EC and osmotic suction.

\section{Conclusion}

The paper studied the effects of quality of water on the behaviour of an expansive soil during wetting and drying cycles. A typical practical application is irrigation channels where alternative cycles of wetting and drying is common,which occurs in where wetting and drying are alternatively a major phenomenon. The following conclusions can be drawn from this study:

- The magnitude of the soil deformation during cycles of wetting and drying under constant surcharge pressure is dependent on the quality of the flooding water.

- Deformations are increased with increasing the cycles of wetting and drying and attain equilibrium state after about four cycles.

- Osmotic suction is dependent on the quality of the flooding water. Deformation and osmotic suction are related to each other, so greater osmotic suction results in greater deformation in the soil.

- Osmotic suction, $\mathrm{pH}$ and EC are decreased with increasing the number of cycles and at the state of equilibrium for deformation, their changes are insignificant. 


\section{References}

Al-Homould, A.S., Basma, A., Husein Malkavi, A.I. Al_Bashabsheh, M.A. 1995. Cyclic swelling behaviour of clays. Journal of Geotechnical Engineering 121:562-565.

Alonso, E.E., Romero, E., Hoffmann, C. Gavcia Escudero, E. 2005. Expansive bentonite-sand mixtures in cyclic controlled suction drying and wetting. Engineering Geology 8: 213-226.

Barbour, S.L Yang, N. 1993. A review of the influence of clay-brine interaction on the geotechnical properties of Ca-montmorillontic claey soils from western Canada, Canadian Geotechnical Journal 30:920-934.

Barbour, S.L. Fredlund, D.G. 1989. Mechanisms of osmotic flow and volume change in clay soils. Canadian Geotechnical Journal 26:551-562.

Basma, A.A., Al-Homould, A.S., Makkavi, A.I.H. Al-Bashabsheh, M.A. 1996. Swelling-shrink behaviour of natural expansive clays. Applied Clay Science 11:211-237.

Bell, F.G. 2000. Engineering properties of soils and rocks. Butterwerth-Heinemann Ltd., Woburn, Ma.

Brady, N.C. 1984. The nature and properties of soils. Macmillan, New York, USA.

Chu, T.Y. Mou, C.H. 1973. Volume change characteristics of expansive soils determined by controlled suction tests. In Proceeding of $3^{\text {rd }}$ International Conference on expansive soils, Haifa, 177-185, 1973.

Day, R.W. 1994. Swell-shrink behaviour of expansive compacted clay. Journal of Geotechnical Engineering 120:618-623. 
Dif, A.F. Blumel, W.F. 1991. Expansive soils under cyclic drying and wetting. Geotechnical Testing Journal 14:96-102.

El-Sohby, M.A. and Rabba, E.A. 1981. Some factors affecting swelling of clayey soils. Geotechnical Engineering 12, 19-39.

Estabragh, A.R., Pereshkafti, M.R.S., Parsaei, B. Javadi, A.A. 2013. Stabilised expansive soil behaviour during wetting and drying. International Journal of Pavement Engineering 14:418-427.

Faramarzi, A., Javadi, A.A. and Alani, A.M. 2012. EPR-based material modelling of soils considering volume changes. Computer \& Geosciences 48:73-85.

Fredlund, D.G. Rahardjo, H. 1993. Soil Mechanics for unsaturated soils. John Wiley \& Sons, New York, USA.

Jones, D.E. Holtz, W.G. 1987. Expansive soils-the hidden disaster. Civil Engineering ASCE, 43:49-51

Mata, C., Romero, E. Ledesma, A. 2002. Hydrochemical effects on water retention in bentonite-sand mixtures. In Proceeding of $3^{\text {rd }}$ International Conference On Unsaturated Soils, Brazil..283-288.

Mckeen, R.G. 1992. A model for predicting expansive soil behaviour. In Proceeding of $7^{\text {th }}$ International Conference on expansive soils. Dallas, USA.1-6.

Mitchell, J.K. 1993. Foundamentals of soil behaviour, $2^{\text {nd }}$ ed. John Wiley \& Sons, New York, USA.

Musso, G., Romero, E., Gens, A. Castellanos. E. 2003. The role of structure in the chemically induced deformation of FEBEX bentonite. Applied Clay Science, 23:229-237.

Osipov, V.I., Bik, n.N. Rumjantsova, N.A. 1987. Cyclic swelling of clays. Applied Clay Science, 2:363-374. 
Rao, S.M. Shivananda, P. 2005. Role of osmotic suction in swelling of salt amended clay. Canadian Geotechnical Journal 42:307-315.

Rao, S.M. Thyagaraj, T. 2007. Role of direction of salt migration on the swelling behaviour of compacted clay. Applied Clay Science 38:113-120

Romero, E. 1999. Characterization and thermo-hydromechanical study. Ph.D thesis, Universidad Politécnica de Cataluna Barcelona, Spain

Tripathy, S., Subba Rao, K.S. Fredlund, D.G. 2002. Water content-void ratio swellshrink path of compacted expansive soils. Canadian Geotechnical Journal 39:938-959.

Rogers,C.D.F., Dijkstra, T.A. Smalley, I.J. 1994. Classification of arid soils for engineering purpose and engineering approach. In Proceeding of $1^{\text {st }}$ Symposium On engineering characteristics of arid soils, 99-134. 


\section{List of figures}

Fig.1 Deformation of samples during wetting and drying cycles with different quality of flooding water

Fig. 2. Variations of $\mathrm{pH}$ for sample flooded with distilled water against time during different cycle for (a) reservoir water, (b) pore water

Fig.3. Variations of $\mathrm{pH}$ for sample flooded with acidic water against time during different cycle for (a) reservoir water, (b) pore water

Fig.4. Variations of $\mathrm{pH}$ for sample flooded with saline water against time during different cycle for (a) reservoir water, (b) pore water

Fig.5. Variations of EC for sample flooded with distilled water against time during different cycle for (a) reservoir water, (b) pore water

Fig.6. Variations of EC for sample flooded with acidic water against time during different cycle for (a) reservoir water, (b) pore water

Fig.7. Variations of EC for sample flooded with saline water against time during different cycle for (a) reservoir water, (b) pore water

Fig.8. Variations of osmotic suction $(\boldsymbol{\pi})$ for samples flooded with distilled water against time for different cycles of wetting and drying

Fig.9. Variations of osmotic suction $(\boldsymbol{\pi})$ for samples flooded with acidic water against time for different cycles of wetting and drying

Fig.10. Variations of osmotic suction $(\boldsymbol{\pi})$ for samples flooded with saline water against time for different cycles of wetting and drying 


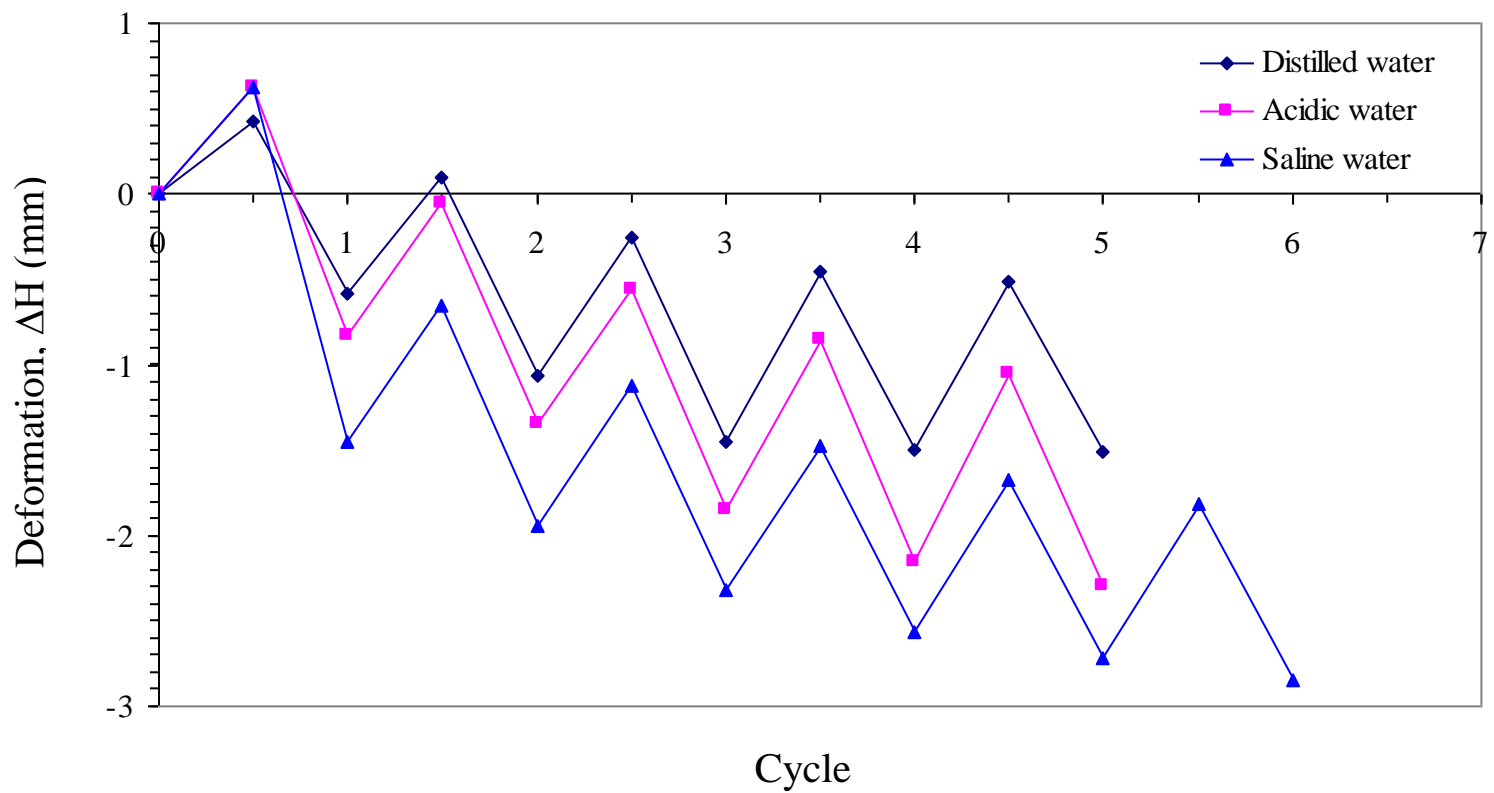

Fig.1 Deformation of samples during wetting and drying cycles with different quality of flooding water 


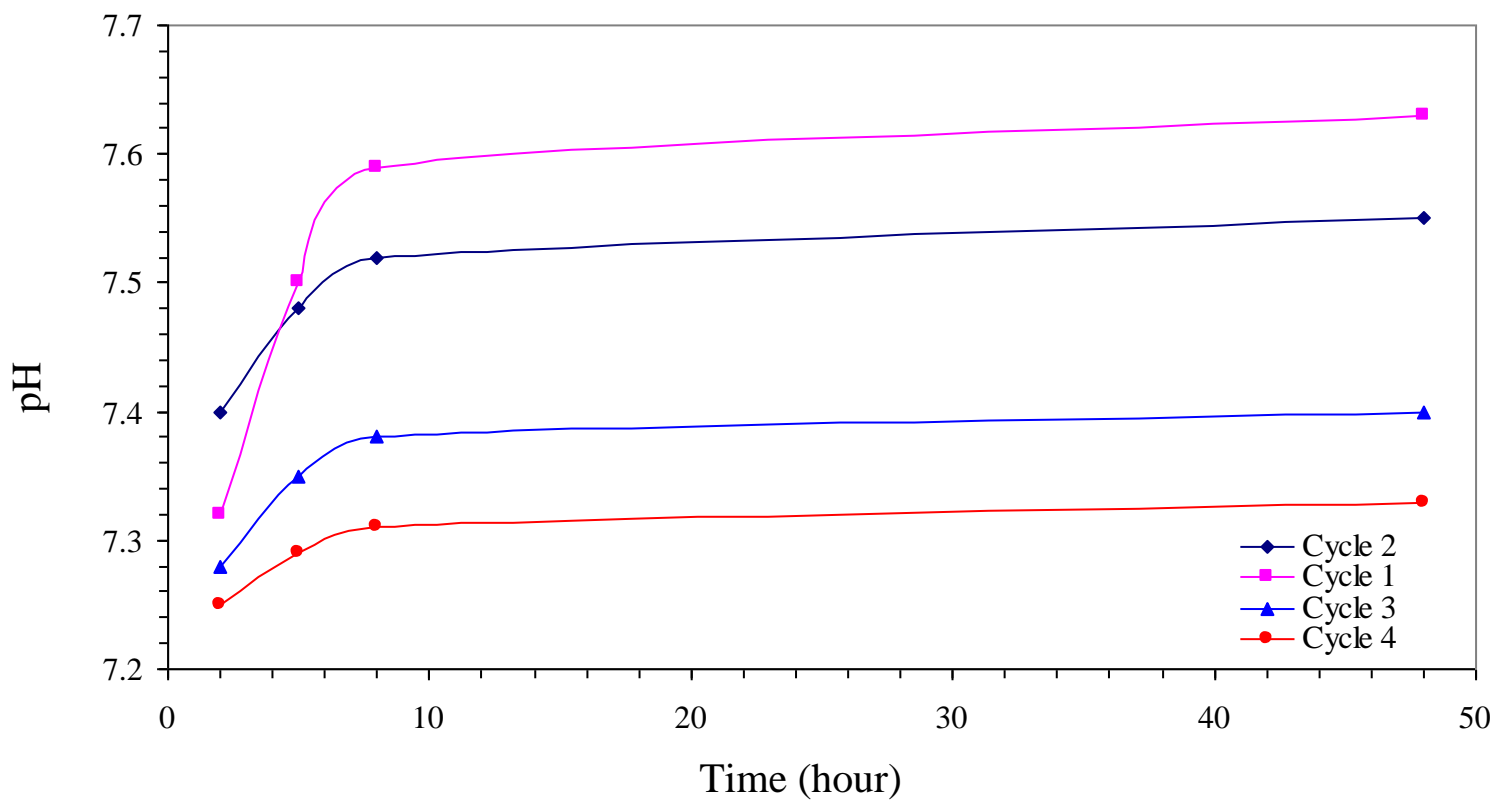

(a)

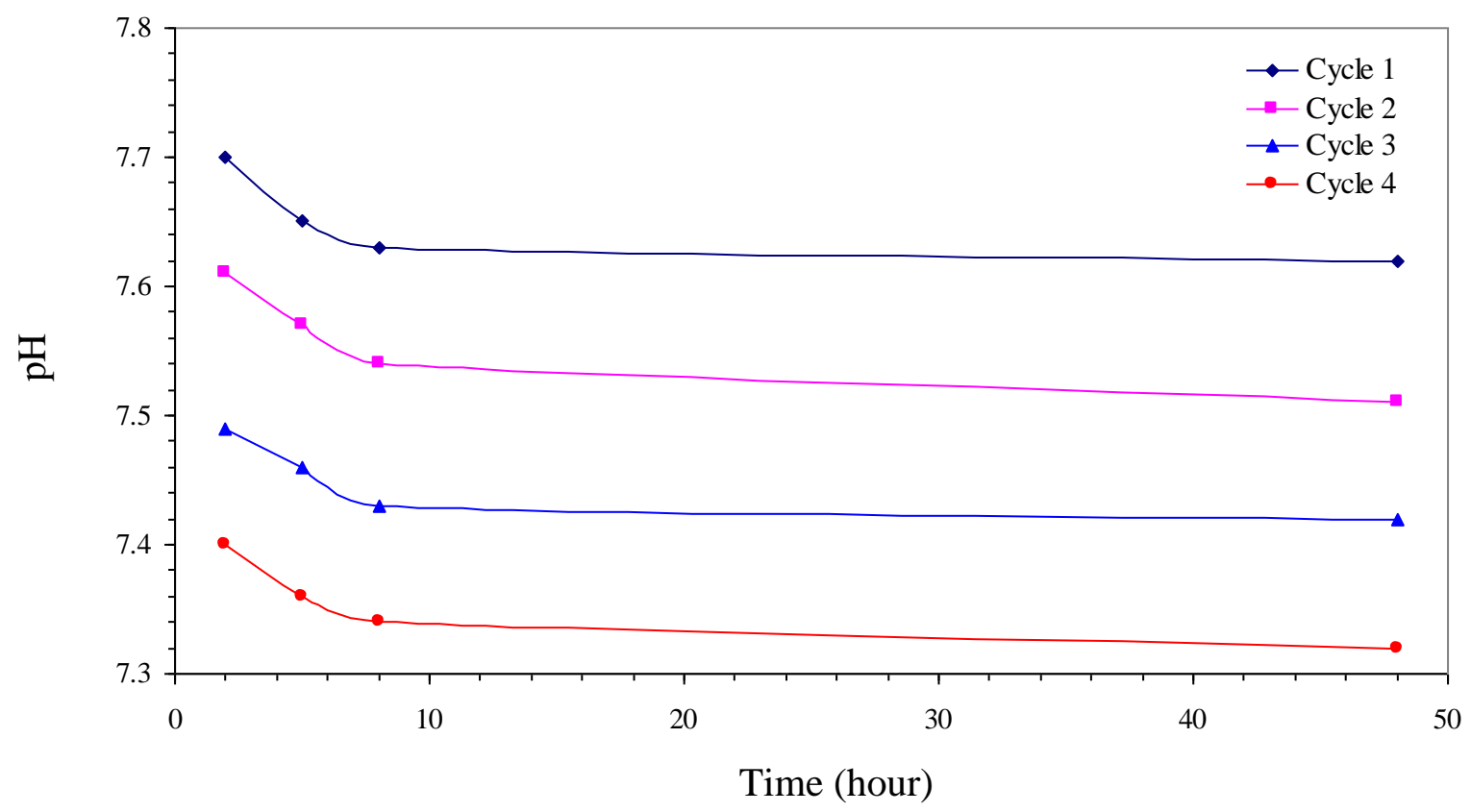

(b)

Fig. 2. Variations of $\mathrm{pH}$ for sample flooded with distilled water against time during different cycle for (a) reservoir water, (b) pore water 


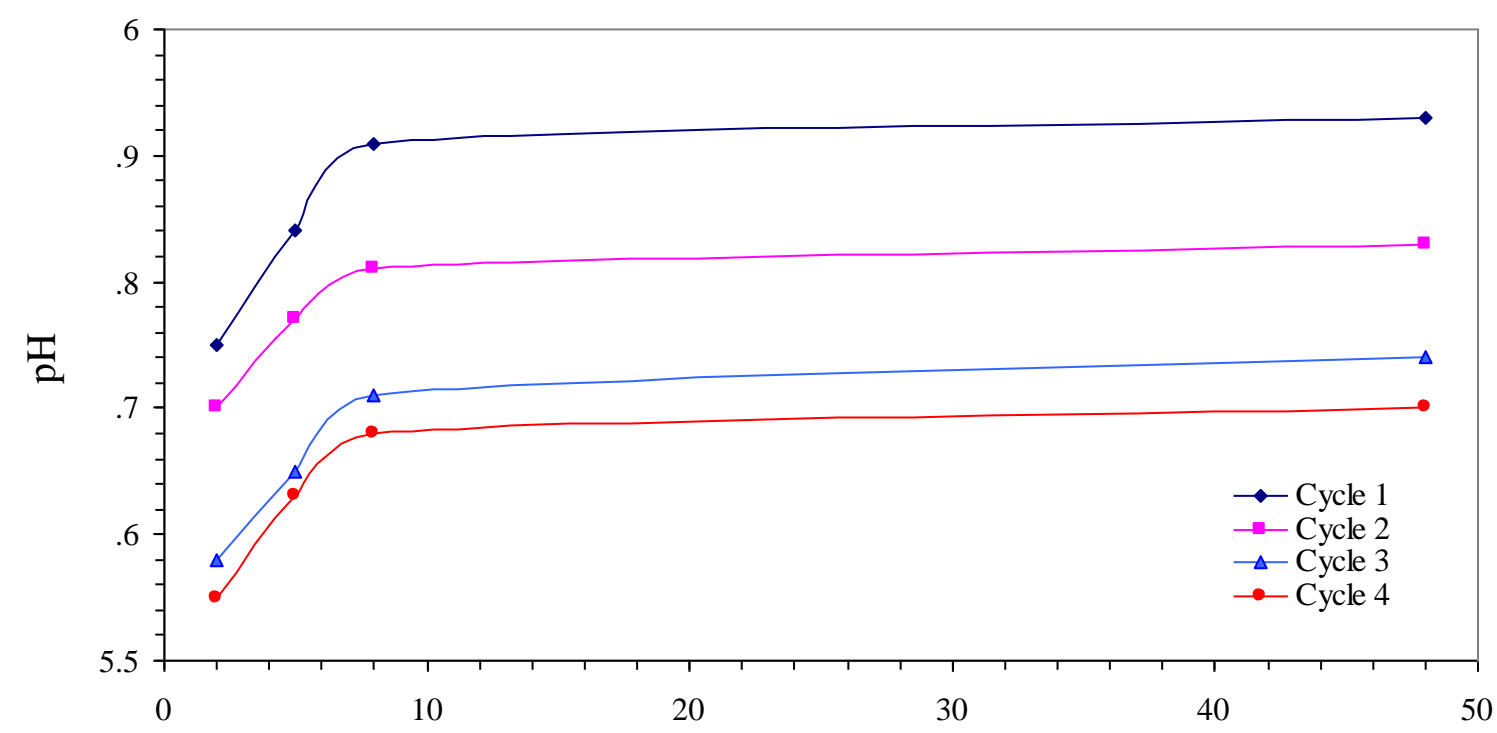

Time (hour)

(a)

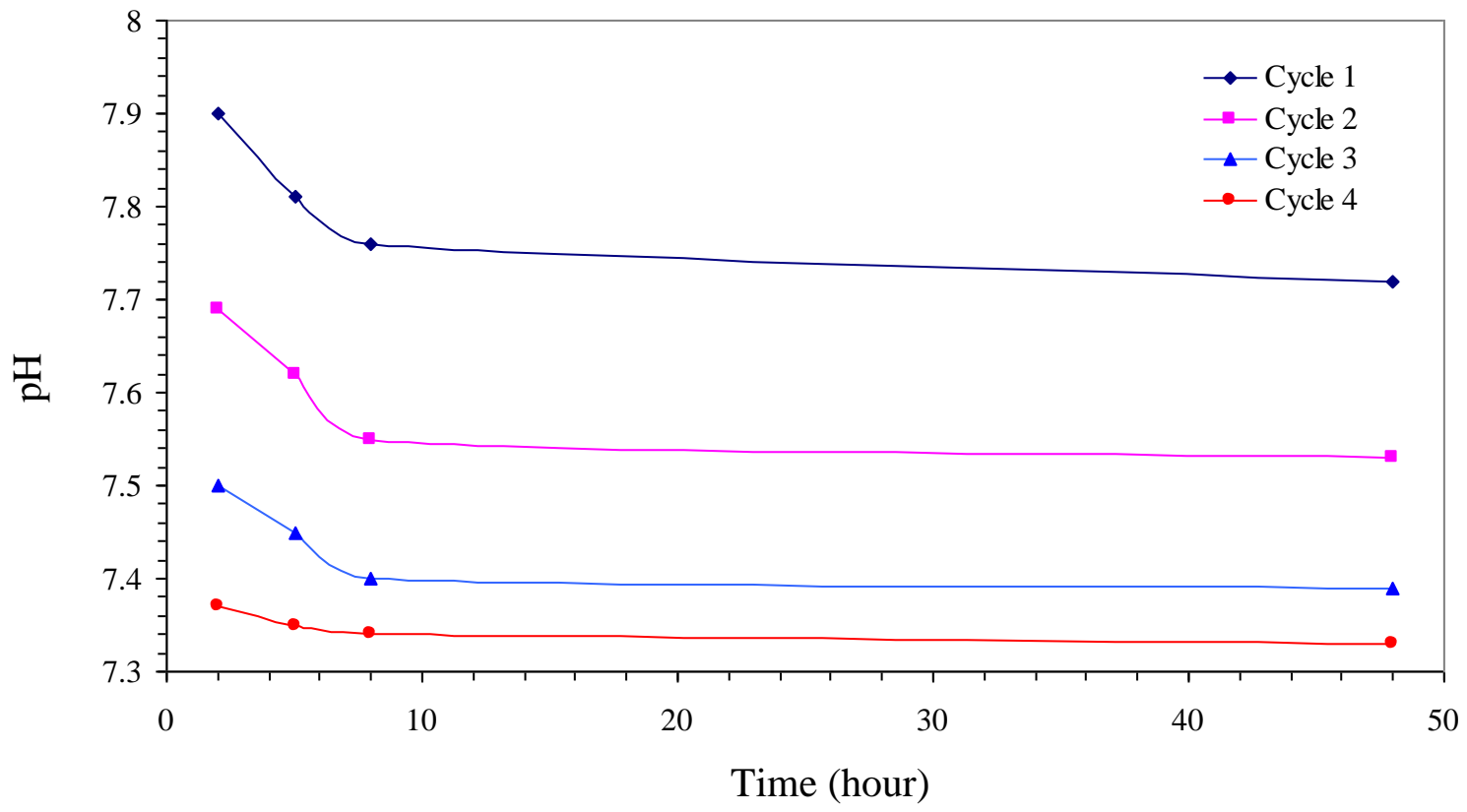

(b)

Fig.3. Variations of $\mathrm{pH}$ for sample flooded with acidic water against time during different cycle for (a) reservoir water, (b) pore water 


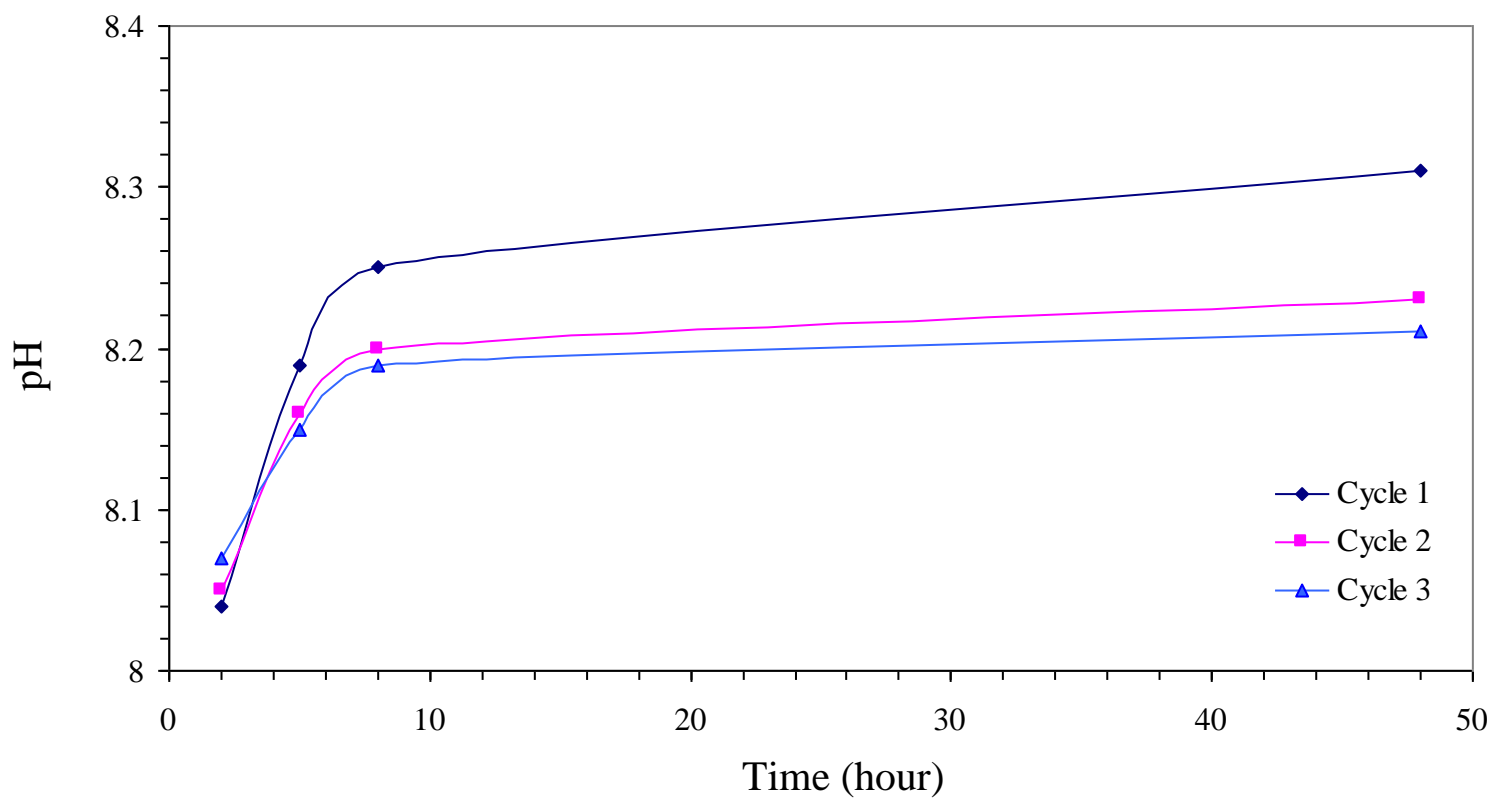

(a)

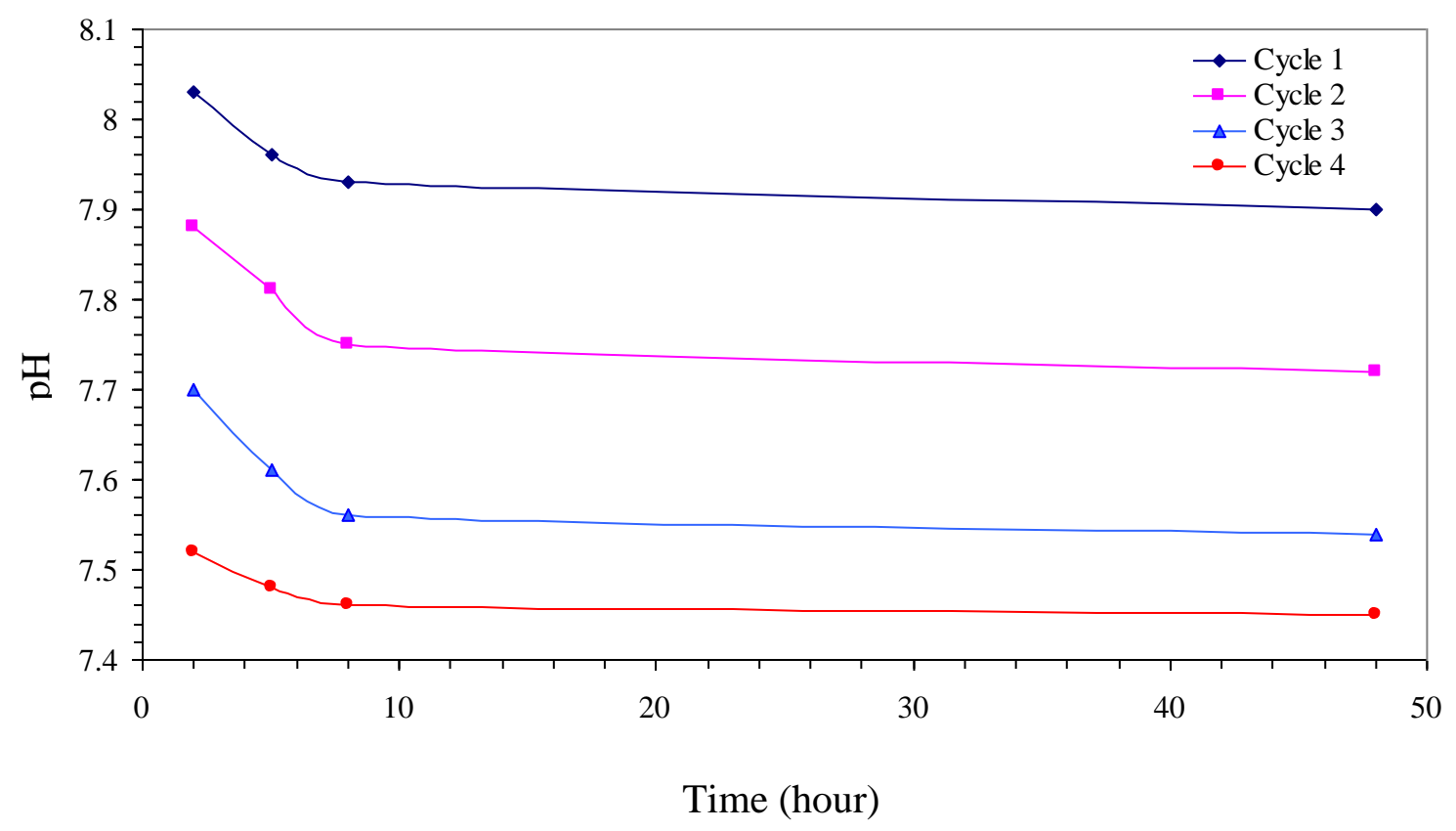

(b)

Fig.4. Variations of $\mathrm{pH}$ for sample flooded with saline water against time during different cycle for (a) reservoir water, (b) pore water 


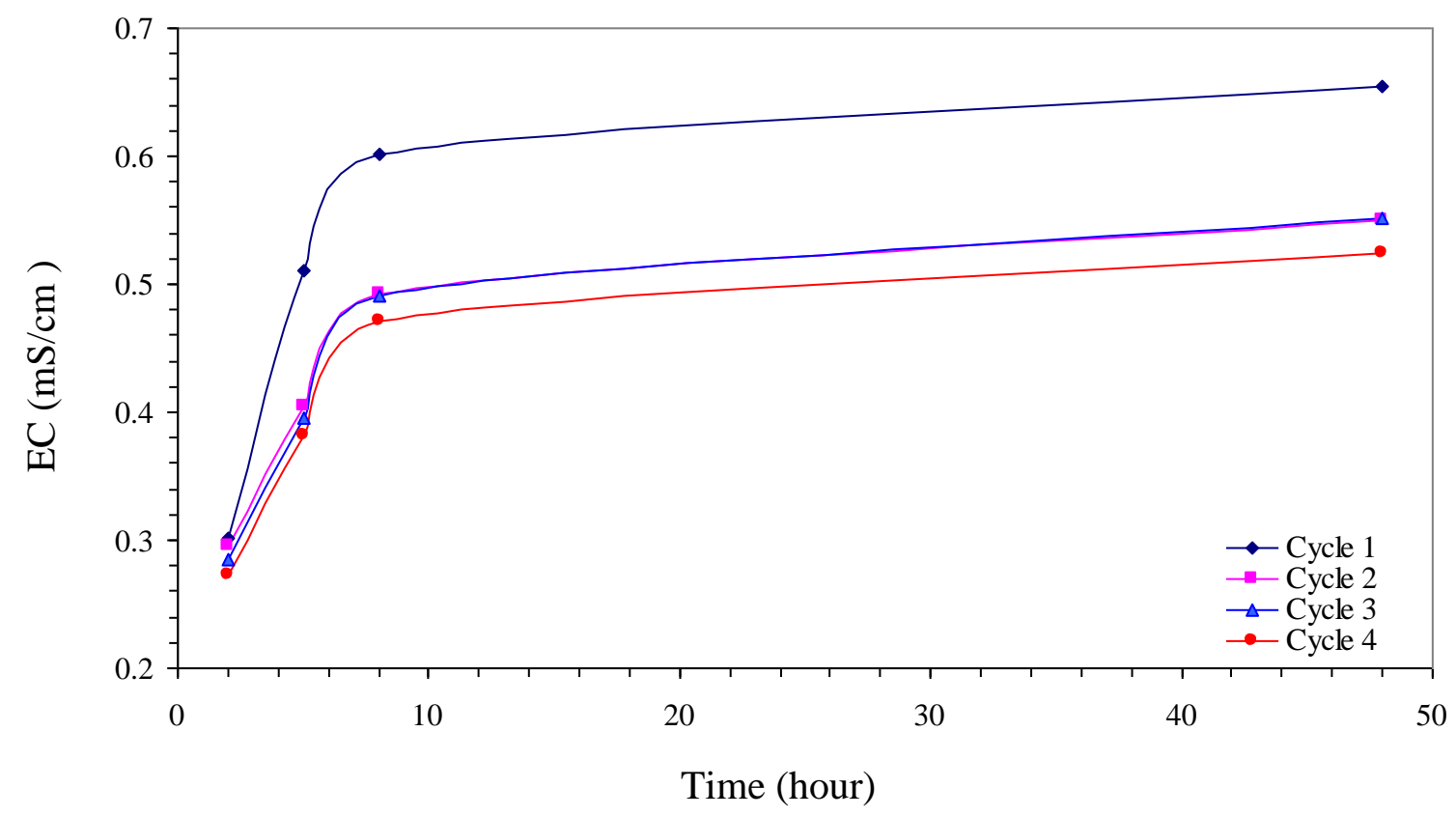

(a)

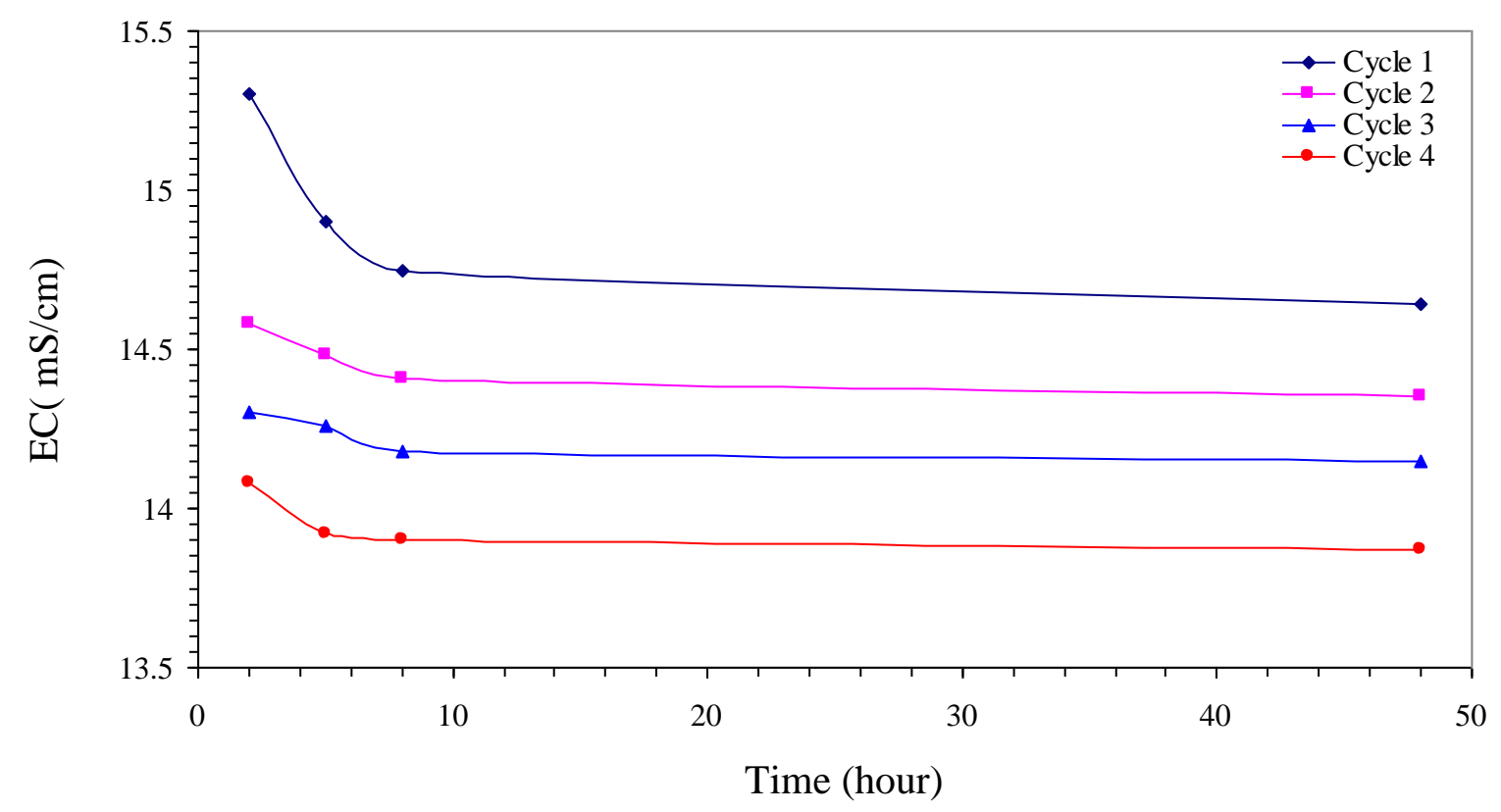

(b)

Fig.5. Variations of EC for sample flooded with distilled water against time during different cycle for (a) reservoir water, (b) pore water 


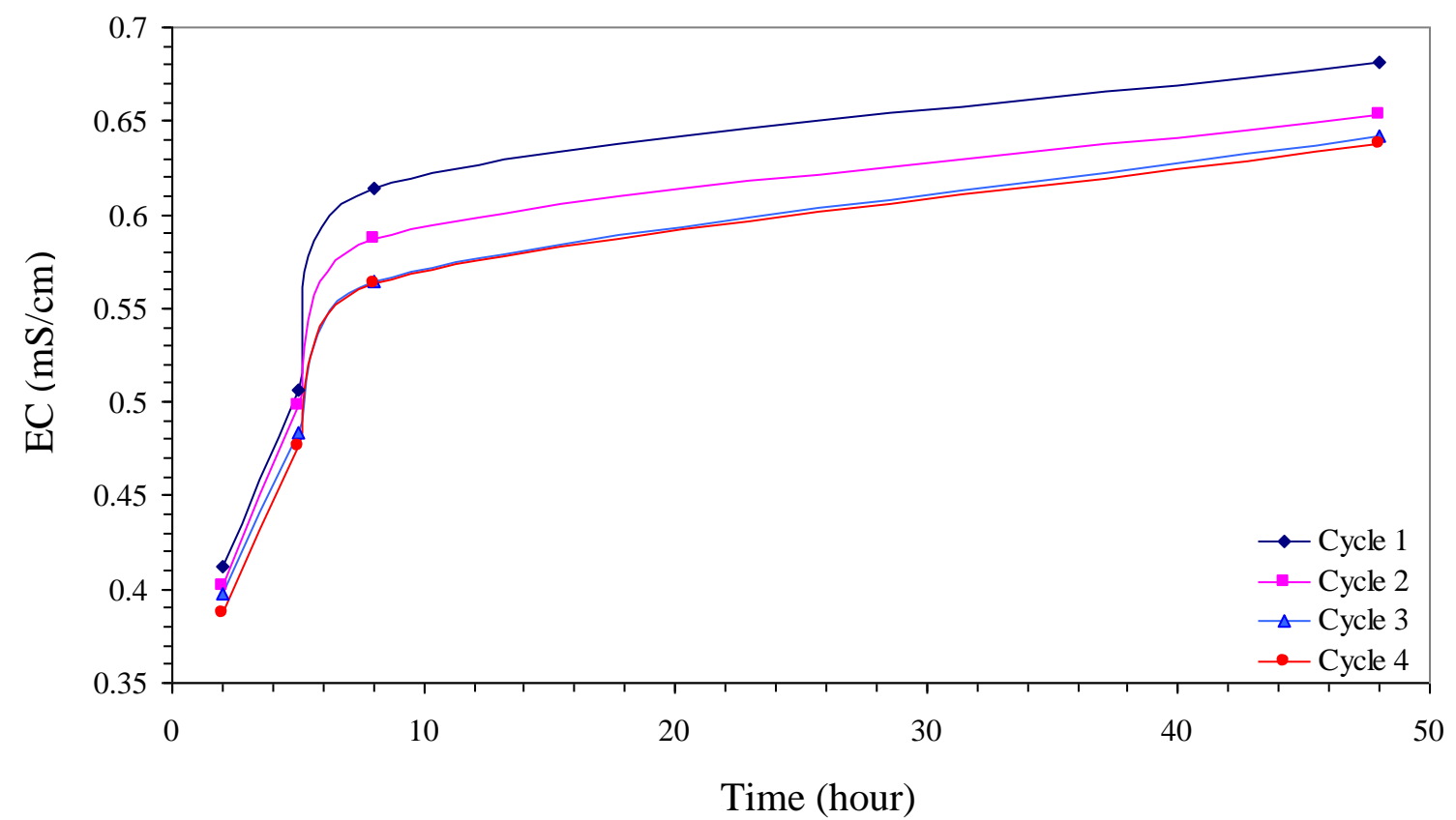

(a)

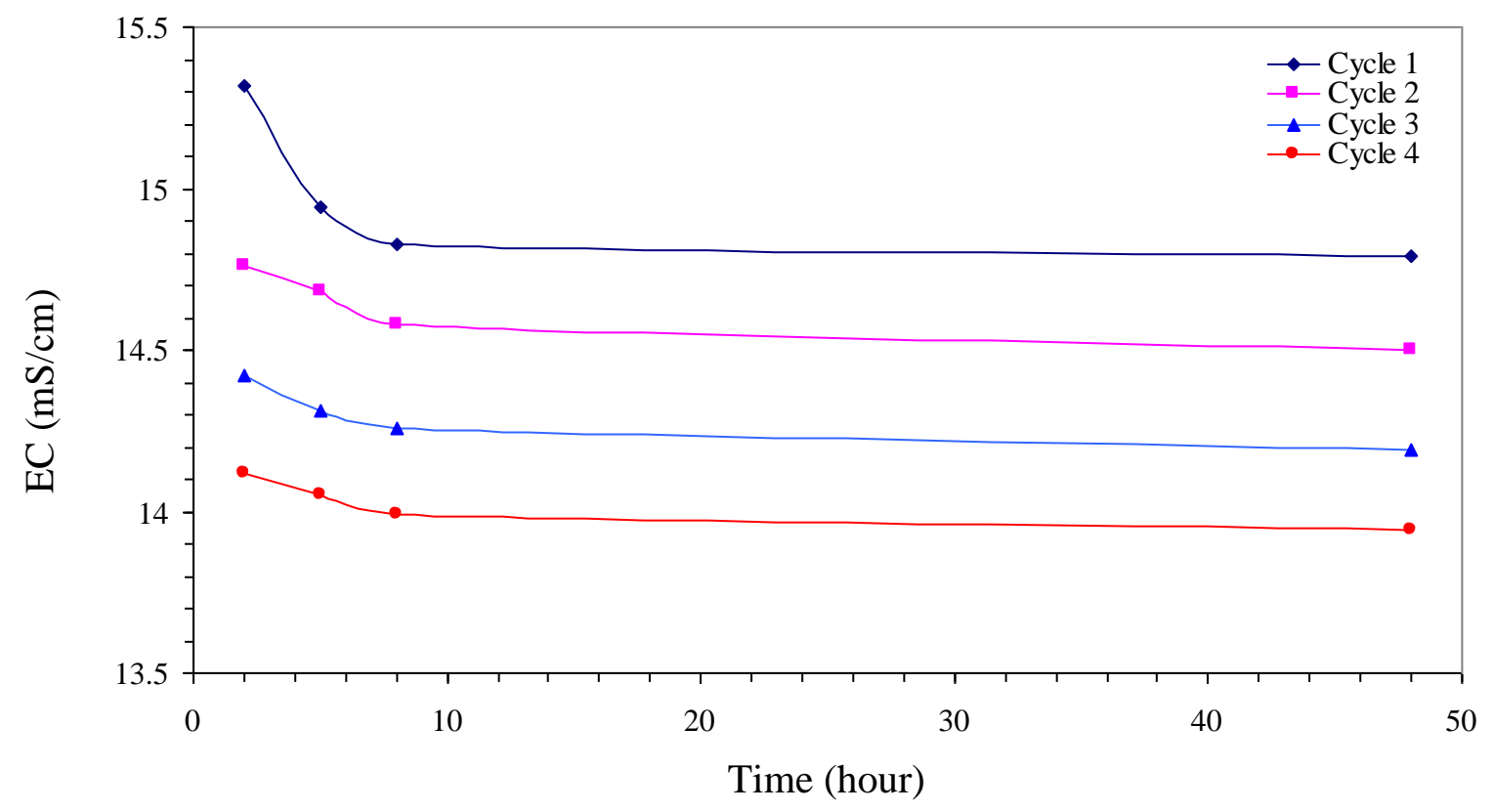

(b)

Fig.6. Variations of EC for sample flooded with acidic water against time during different cycle for (a) reservoir water, (b) pore water 


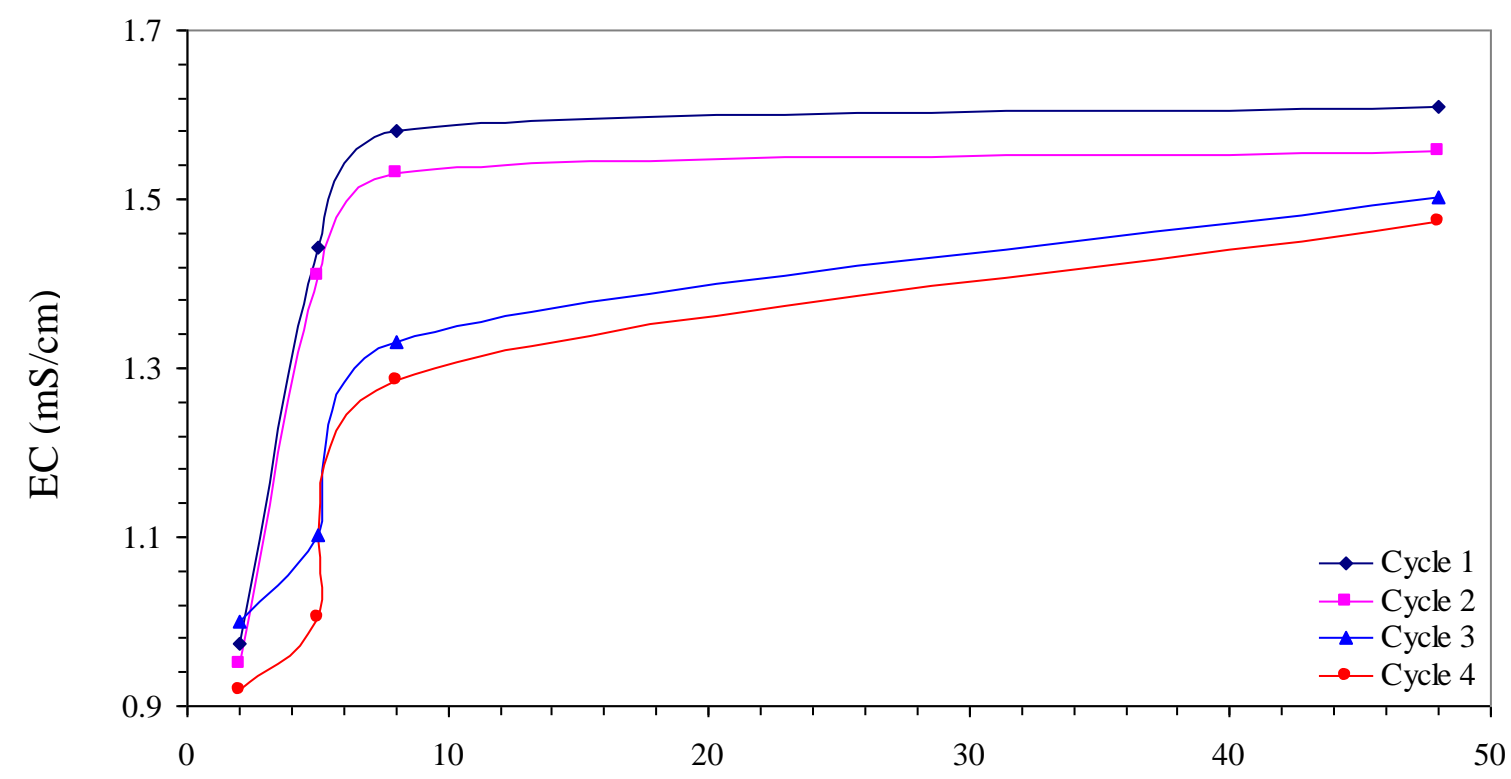

Time (hour)

(a)

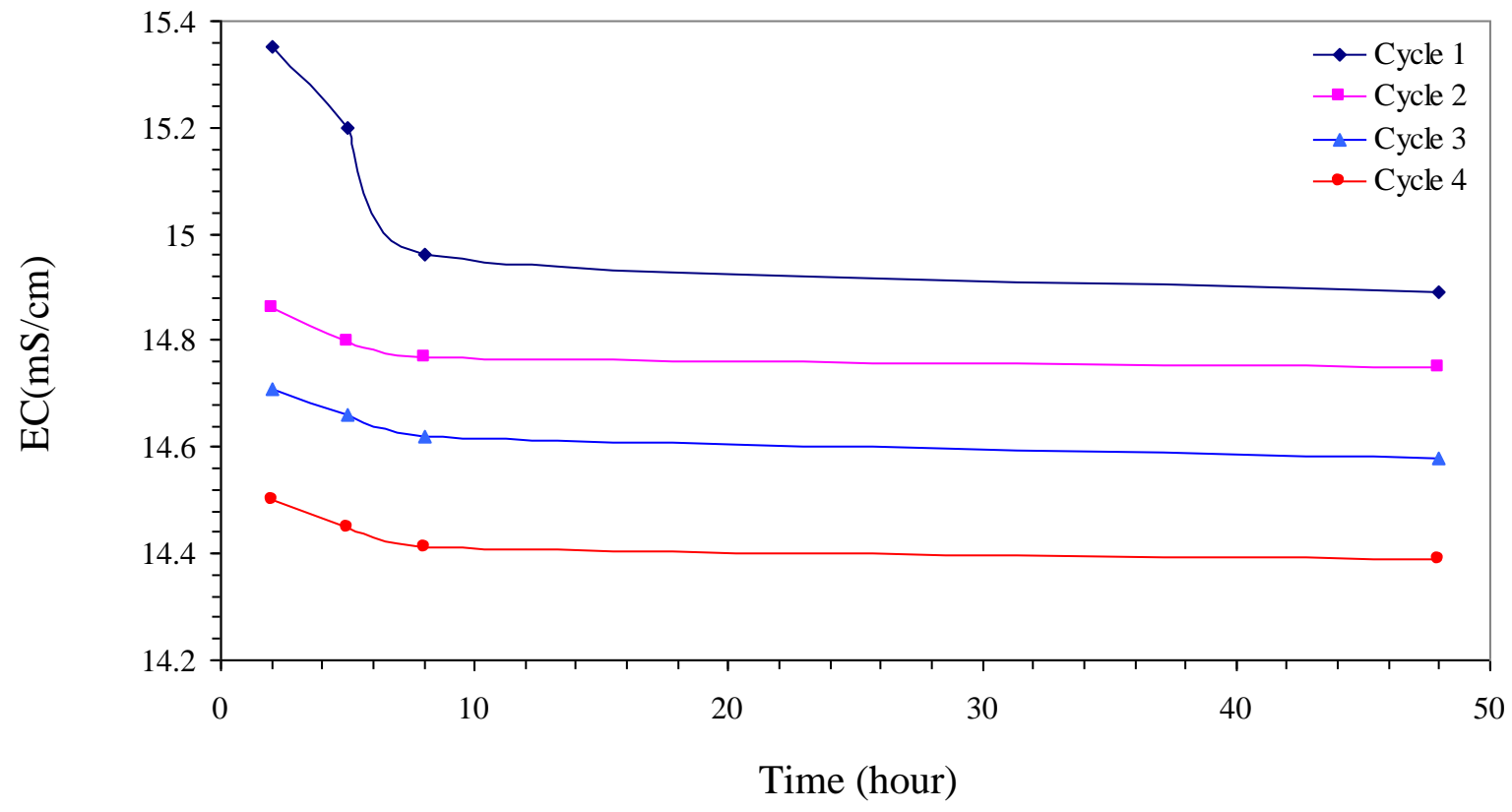

(b)

Fig.7. Variations of EC for sample flooded with saline water against time during different cycle for (a) reservoir water, (b) pore water 


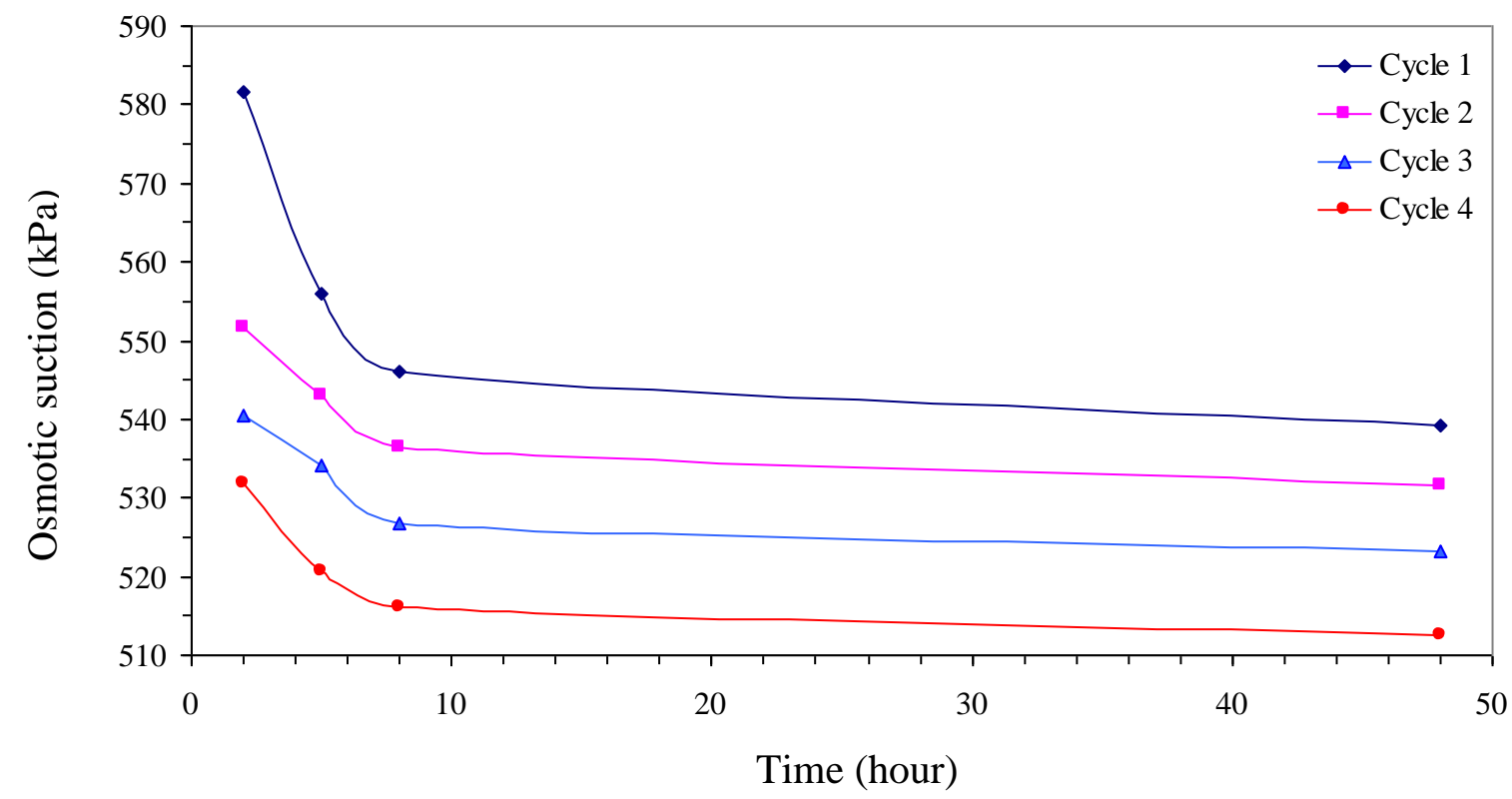

Fig.8. Variations of osmotic suction $(\boldsymbol{\pi})$ for samples flooded with distilled water against time for different cycles of wetting and drying

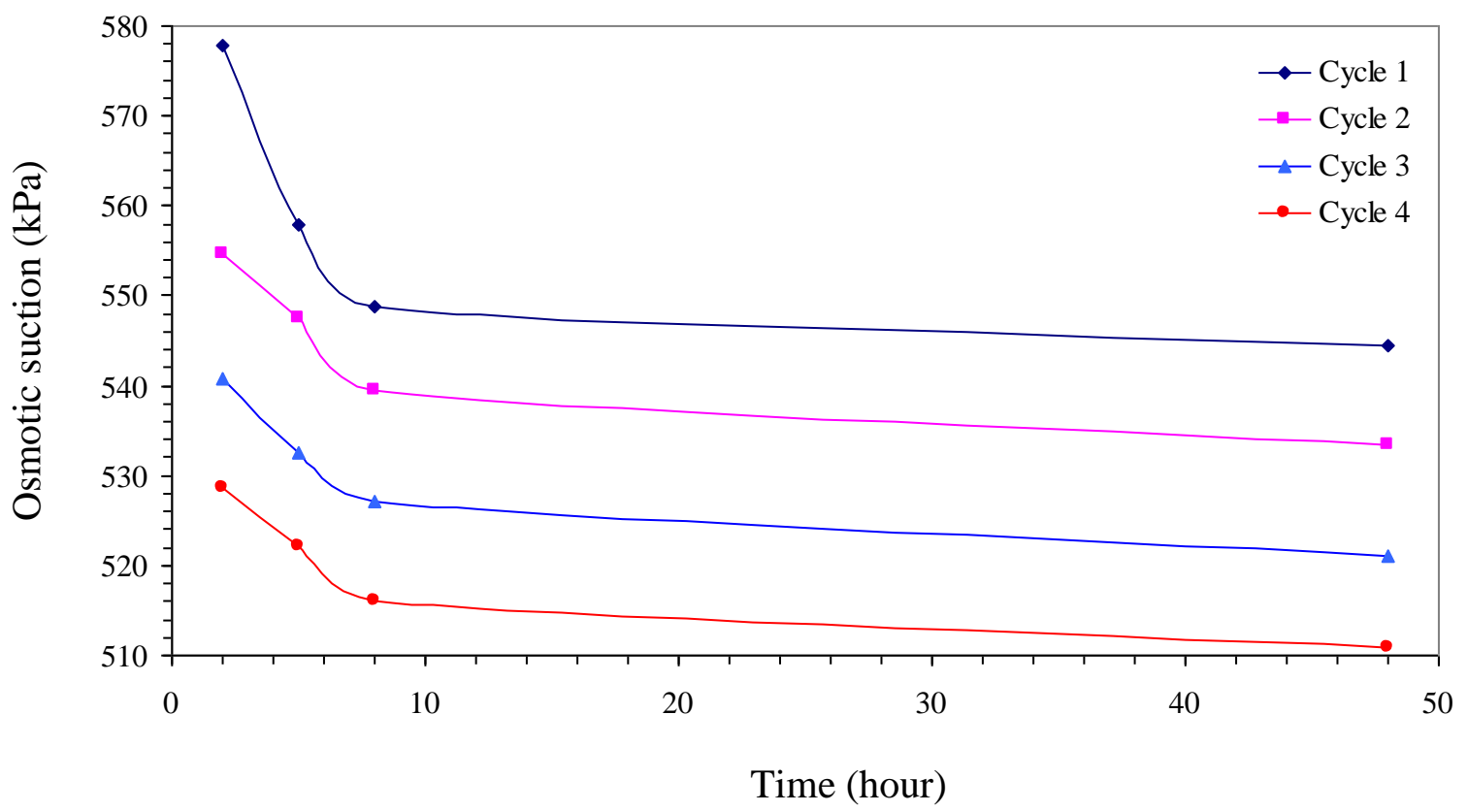

Fig.9. Variations of osmotic suction $(\boldsymbol{\pi})$ for samples flooded with acidic water against time for different cycles of wetting and drying 


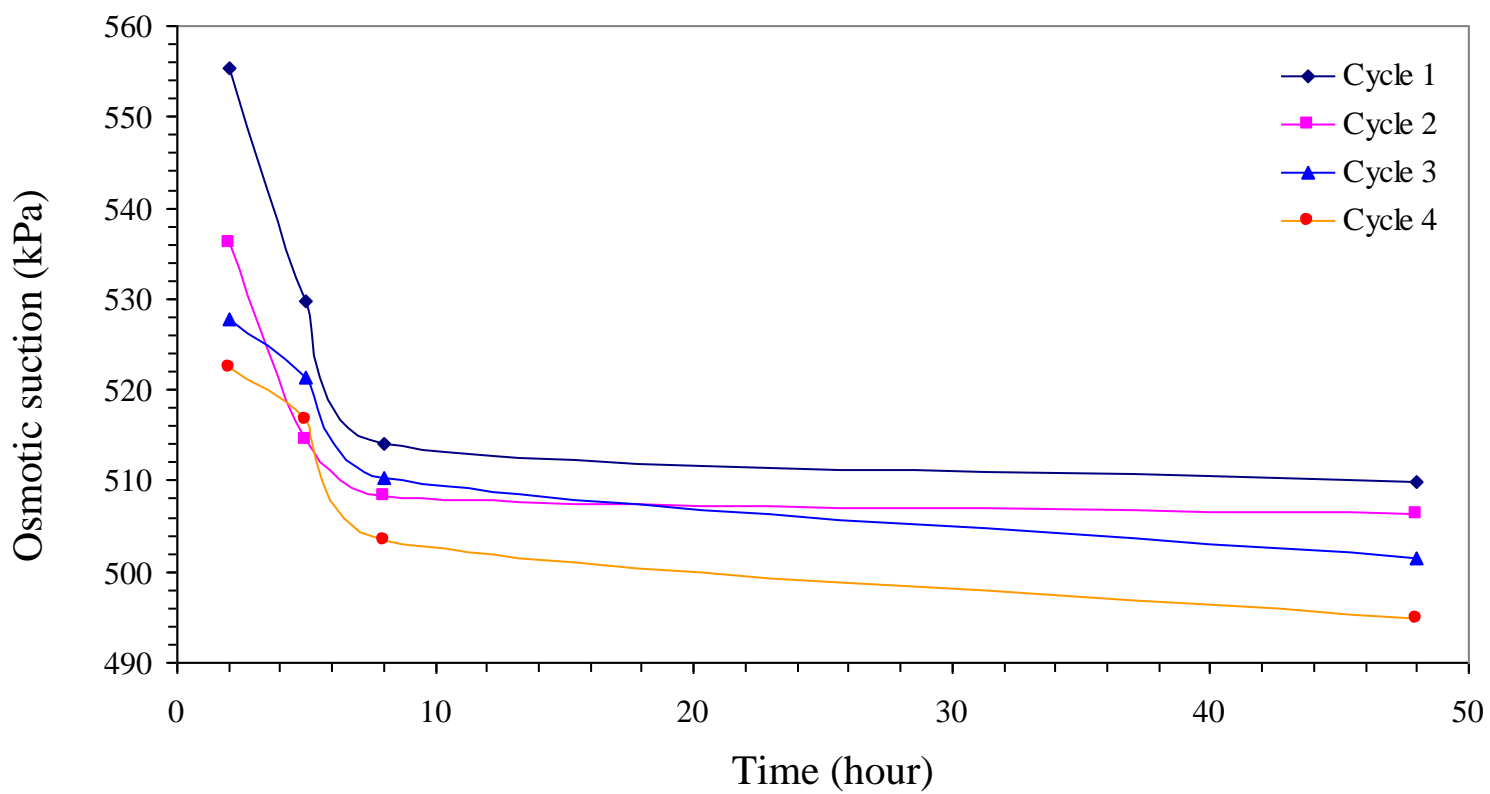

Fig.10. Variations of osmotic suction $(\boldsymbol{\pi})$ for samples flooded with saline water against time for different cycles of wetting and drying 


\section{List of tables}

Table 1. Physical and mechanical properties of the soil

Table 2. Chemical composition of the soil 
Table 1. Physical and mechanical properties of the soil

\begin{tabular}{|lc|}
\hline Soil properties & Values \\
\hline Specific gravity & 2.75 \\
Consistency limits & \\
Liquid limit (LL) & $70 \%$ \\
Plastic limit (PL) & $23 \%$ \\
Plastic index (PI) & $47 \%$ \\
Shrinkage limit (SL) & $13 \%$ \\
USCS classification & $\mathrm{CH}$ \\
Swelling pressure & $120 \mathrm{kPa}$ \\
Compaction study & \\
Optimum water content & $18 \%$ \\
Maximum dry density & \\
Grain size analysis & \\
Sand & \\
\hline Clay & $27 \%$ \\
\hline
\end{tabular}


Table 2. Chemical composition of the soil

\begin{tabular}{|lc|}
\hline Chemical component & Amount \\
\hline $\mathrm{Na}^{+}(\mathrm{meq} / \mathrm{L})$ & 73.5 \\
$\mathrm{~K}^{+}(\mathrm{meq} / \mathrm{L})$ & 0.04 \\
$\mathrm{Ca}^{2+}(\mathrm{meq} / \mathrm{L})$ & 8.4 \\
$\mathrm{Mg}^{2+}($ meq/L) & 4.9 \\
$\mathrm{Cl}^{-}($meq/L) & 35.6 \\
$\mathrm{CO}_{3}^{2-}(\mathrm{meq} / \mathrm{L})$ & 0.1 \\
$\mathrm{SO}_{4}^{2-}(\mathrm{meq} / \mathrm{L})$ & 50.8 \\
$\mathrm{HCO}_{3}^{-}(\mathrm{meq} / \mathrm{L})$ & 31.1 \\
$\mathrm{pH}^{\mathrm{Electrical} \mathrm{conductivity}(\mu \mathrm{S} / \mathrm{cm})}$ & 8.2 \\
\hline
\end{tabular}

